\title{
Management of sepsis and septic shock in the emergency department
}

\author{
Francesco Gavelli ${ }^{1,2} \cdot$ Luigi Mario Castello ${ }^{1,2} \cdot$ Gian Carlo Avanzi ${ }^{1,2}$
}

Received: 8 February 2021 / Accepted: 30 March 2021 / Published online: 22 April 2021

(c) The Author(s) 2021

\begin{abstract}
Early management of sepsis and septic shock is crucial for patients' prognosis. As the Emergency Department (ED) is the place where the first medical contact for septic patients is likely to occur, emergency physicians play an essential role in the early phases of patient management, which consists of accurate initial diagnosis, resuscitation, and early antibiotic treatment. Since the issuing of the Surviving Sepsis Campaign guidelines in 2016, several studies have been published on different aspects of sepsis management, adding a substantial amount of new information on the pathophysiology and treatment of sepsis and septic shock. In light of this emerging evidence, the present narrative review provides a comprehensive account of the recent advances in septic patient management in the ED.
\end{abstract}

Keywords Fluid resuscitation $\cdot$ Preload responsiveness $\cdot$ Vasopressors $\cdot$ Emergency medicine $\cdot$ Antibiotic therapy

\section{Introduction}

The management of septic patients is one of the main challenges for emergency physicians. Sepsis is indeed a lifethreatening organ dysfunction caused by a dysregulated host response to infection. Septic shock is a subset of sepsis, where circulatory, cellular, and metabolic abnormalities are responsible for increased mortality [1]. According to the Sepsis-3 definitions, a new algorithm involving both the Sequential Organ Failure Assessment (SOFA) and the quickSOFA scores allows a homogeneous identification of septic patients [1] (Fig. 1). The 2016 Surviving Sepsis Campaign (SCC) [2] has provided guidelines for the management of septic patients, but the 2018 update of the SCC Bundle has stressed the need for a prompt—-the hour-1 bundle—-beginning of the resuscitations procedures [3].

As sepsis is a time-dependent disease, and the first medical contact of such patients takes place at the Emergency Department (ED) $[4,5]$, the need for early recognition and risk stratification has led to identify many prognostic markers that could help the emergency physician implement a

Francesco Gavelli

francesco.gavelli@uniupo.it

1 Department of Translational Medicine, Università del Piemonte Orientale UPO, Via Solaroli 17, Novara, Italy

2 Emergency Medicine Department, AOU Maggiore Della Carità, Corso Mazzini 18, Novara, Italy more aggressive and effective disease management [6-10]. Nevertheless, in-hospital mortality still remains high, with rates of up to $40 \%$ in Europe and North America [11].

The aim of this narrative review is to summarize the main pathophysiological features of sepsis and septic shock, and to provide a comprehensive overview of the recent improvements in the first-line management of these conditions.

\section{Hemodynamic alterations}

From a hemodynamic perspective, septic shock is characterized by the presence of simultaneous alterations at both the macrocirculation and microcirculation levels, resulting in an inadequate balance between oxygen demand and oxygen delivery [12].

\section{Derangements of macrocirculation}

One of the main effects of a dysregulated inflammatory response in septic shock patients, alongside increased vascular permeability, is the depression of the vascular tone, which leads to a profound venous and arterial vasodilation [13]. Such condition is associated with a status of absolute and relative hypovolemia. The immediate clinical implication is represented by a sudden drop in arterial blood pressure, which is more evident in the diastolic component. Simultaneously, venous dilation leads to a marked reduction 


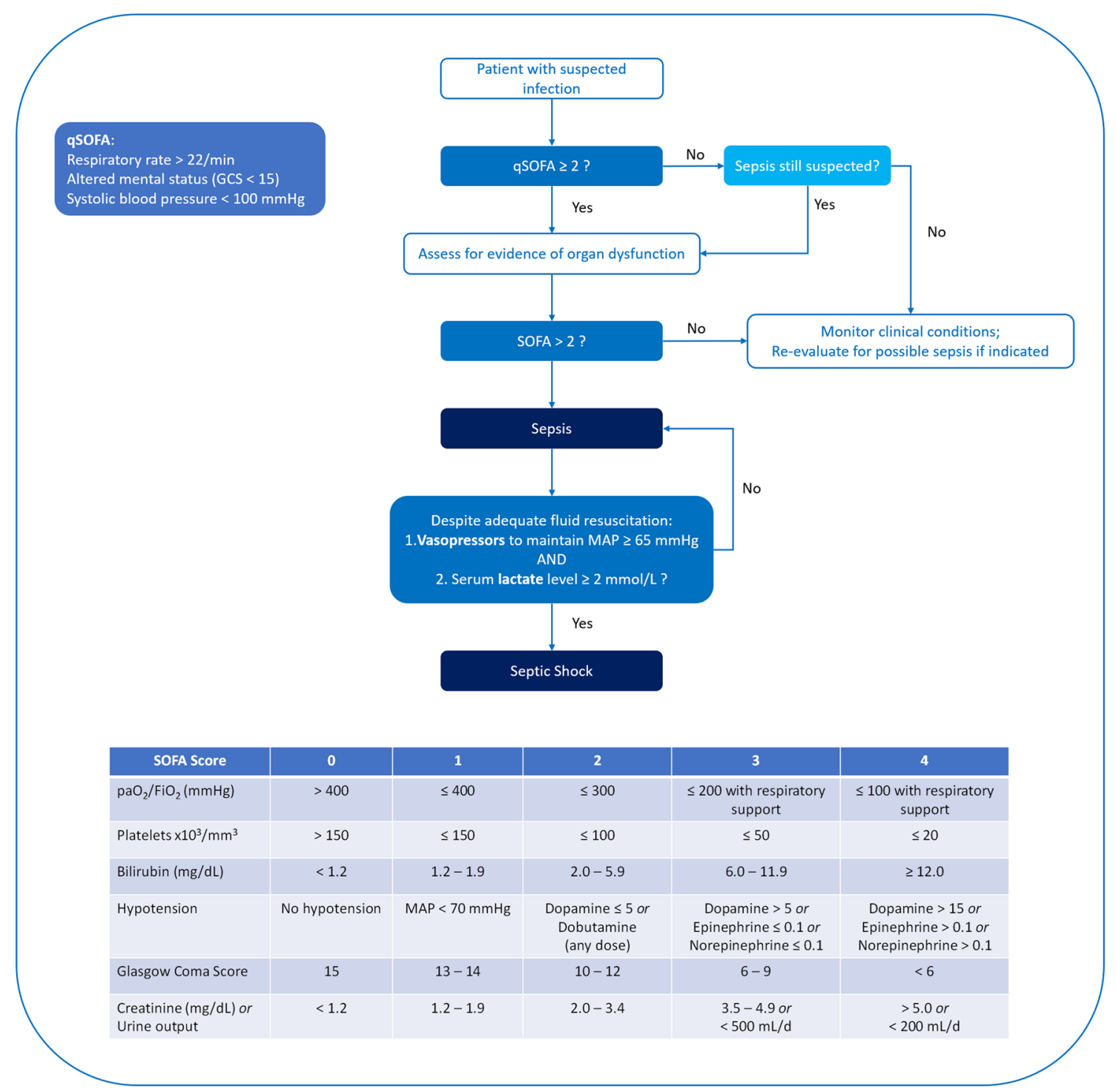

Fig. 1 Clinical criteria for sepsis and septic shock definition. Adapted from [1]. SOFA Sequential Organ Failure Assessment, qSOFA quickSOFA

in the amount of stressed blood volume, thereby decreasing both venous return and cardiac output (CO), with further impairment of oxygen distribution to the tissues [14].

From a clinical perspective, the decrease in ventricular preload due to venodilation and hypovolemia is signaled by a drastic decrease in central venous pressure (CVP) [15], which triggers the activation of different neurohormonal factors aimed to maintain adequate organ perfusion, strictly dependent on the mean arterial pressure (MAP) [16]. The activation of the sympathetic tone through the stimulation of $\alpha$ - and $\beta$-adrenergic receptors increases both the heart rate and the cardiac contractility. At the same time, vasoconstriction induced by the stimulation of $\alpha$-adrenergic receptors improves the arterial tone, which ultimately results in increased MAP. The activation of $\alpha$-adrenergic receptors on veins, on the other hand, increases the venous tone, recruiting unstressed volume into stressed volume.

As the overall purpose of these series of events is to "pressurize" the circulatory system, the poor vascular response to vasoactive stimulation in septic shock patients due to adrenal insufficiency and the presence of high levels of vasodilator substances, such as oxide nitric [17], renders these compensatory mechanisms far less effective than in other forms of shock [13]. The efficacy of this compensatory response is further worsened by the impaired intrinsic contractility of both ventricles, which is observed in about $60 \%$ of septic patients [18]. Such condition, called septic cardiomyopathy, can either be present at the time of sepsis onset or appear over the following days, and seems to be related to endothelial and mitochondrial impairment, alteration of $\beta$-adrenergic 
receptors and myocardial calcium metabolism [18]. Even though cardiomyopathy is reversible once sepsis is resolved, it is an issue that the emergency physician should carefully take into account when treating septic patients, as it may hamper the efficacy of both compensatory mechanisms and therapeutic maneuvers.

\section{Derangement of microcirculation}

Under normal conditions, oxygen delivery $\left(\mathrm{DO}_{2}\right)$ to the tissues is higher than what is required for oxygen consumption $\left(\mathrm{VO}_{2}\right)$, and the relationship between metabolic demands of the tissues and $\mathrm{DO}_{2}$ is represented by the central venous saturation $\left(\mathrm{ScvO}_{2}\right)$ of hemoglobin [12]. In case of either increased $\mathrm{O}_{2}$ demand or reduced delivery, oxygen extraction increases, and this is reflected by a reduction in $\mathrm{ScvO}_{2}-$ commonly used in place of the mixed venous saturation. However, below a certain level of $\mathrm{DO}_{2}$, called "critical $\mathrm{DO}_{2}$ ", oxygen extraction cannot further increase, and $\mathrm{ScvO}_{2}$ cannot further decrease, making it impossible to meet the metabolic demands, which will now strictly depend on the amount of available oxygen ( $\mathrm{DO}_{2} / \mathrm{VO}_{2}$ dependency) [12] (Fig. 2).

However, the fact that in septic shock the critical threshold of $\mathrm{DO}_{2}$ is higher than in any other forms of shock determines an almost immediate impairment of oxygen extraction from the tissues. It is thus very common to observe normal $\mathrm{ScvO}_{2}$ values in such patients [19]. The various mechanisms underlying this condition can range from microvascular derangements [20] to cellular dysoxia [21], with the latter responsible for curbing aerobic glycolysis, leading to the accumulation of lactate (Fig. 2).

\section{Fluid therapy}

Fluid administration, together with antibiotic therapy, is the first-line therapy for septic shock patients [2]. The aim of this treatment is to correct hypovolemia by increasing the amount of stressed blood volume, with consequent increase in venous return and cardiac preload, expected to increase CO and, ultimately, oxygen delivery [14]. Nevertheless, after the initial phases of resuscitation, half of the patients will eventually become non-fluid responsive, a condition where the administration of a fluid bolus may lead to fluid accumulation, impaired $\mathrm{DO}_{2}$, and defective venous return, worsening the organ perfusion pressure [14]. Thus, over the years various tests have been developed to predict fluid responsiveness in septic shock patients. Among them, the passive leg raising (PLR) test has gained a lot of consensus as it is easy to perform and particularly suitable for the ED setting [22]. By moving the patient from a semi-recumbent position,

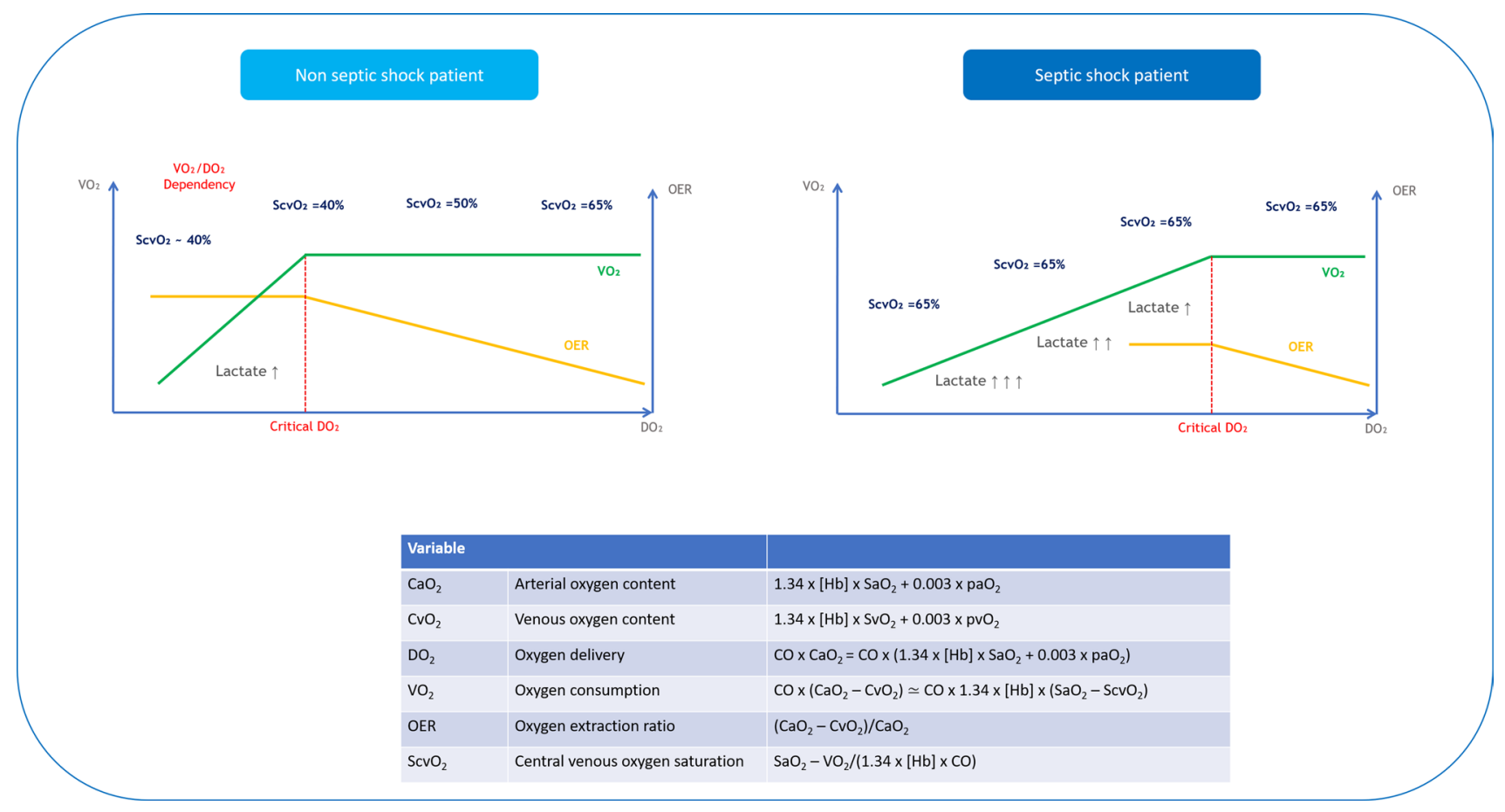

Fig. $2 \mathrm{DO}_{2} / \mathrm{VO}_{2}$ relationship in patients with or without septic shock. $\mathrm{CaO}_{2}$ arterial oxygen content, $\mathrm{CO}$ cardiac output, $\mathrm{CvO}$ venous oxygen content, $\mathrm{DO}_{2}$ oxygen delivery, $\mathrm{Hb}$ hemoglobin, $\mathrm{OER}$ oxygen extraction ratio, $\mathrm{paO}_{2}$ arterial partial pressure of oxygen, $\mathrm{pvO} \mathrm{O}_{2}$ venous partial pressure of oxygen, $\mathrm{SaO}_{2}$ arterial oxygen saturation, $\mathrm{ScvO}$ central venous oxygen saturation, $\mathrm{SvO}_{2}$ mixed venous oxygen saturation, $\mathrm{VO}_{2}$ oxygen consumption 
lowering the trunk and raising the patient's legs to $45^{\circ}$, an amount of $\sim 300 \mathrm{~mL}$ of blood is transferred to the ventricles, thereby increasing the cardiac preload. If $\mathrm{CO}$ increases of at least 10\% compared to baseline, the patient is considered preload responsive, thus capable of displaying a $\mathrm{CO}$ increase following administration of fluid. To detect the effects of a PLR test, it is recommended to adopt a method of continuous CO monitoring [23].

It is however important to point out that any septic shock patient admitted to the ED should be considered fluid responsive and immediately treated with a fluid bolus [24]. In this regard, the 2016 SCC guidelines, recommending a fixed dose of $30 \mathrm{~mL} / \mathrm{kg}$ of crystalloids within the first $3 \mathrm{~h}$ [2], sparked an intense debate among clinicians. On the one hand, the timeframe of $3 \mathrm{~h}$ before patient revaluation seemed too long for a time-dependent disease such as septic shock. On the other hand, the recommended amount of fluid was deemed too liberal, hardly suitable for all patients [25]. These concerns were further justified by the lack of highquality data supporting these recommendations.

The 2018 SCC bundle update partially resolved this controversy by switching from the previously recommended 3and $6 \mathrm{~h}$ bundles to an hour- 1 bundle, recognizing the need for an immediate treatment of septic patients [3]. Nonetheless, no changes to the protocol were made to personalize fluid administration, as advocated by many. In this regard, Teboul and Monnet have recently proposed to start fluid administration with an infusion of $\sim 10 \mathrm{~mL} / \mathrm{kg}$ within the first 30 to $60 \mathrm{~min}$ while closely monitoring the patient [25]. In case of worsening of tachypnea or a drop in oxygen saturation, the amount of fluid should be reduced. Conversely, an increase in the infusion rate should be considered if signs of low arterial pulse pressure, increased capillary refill time, or skin mottling were to persist despite initial fluid treatment. We fully agree with this approach because we feel that the decision to continue fluid administration should be based on the individualized risk/benefit ratio of the patient, using dynamic tests of preload responsiveness to evaluate the benefit of further fluid infusion.

\section{What kind of fluid should the patient be given?}

The 2016 SCC guidelines suggest the use of crystalloids for fluid resuscitation of septic patients [2], but over the years different types of fluids have been proposed. Among them, the use of synthetic colloids, such as hydroxyethyl-starch solutions (HES), was based on the assumption that their intravascular volume expansion would have been superior to that of crystalloids [26]. After the publication of several studies indicating that HES treatment was associated with increased renal damage and mortality $[27,28]$ and the retraction of many articles supporting the use of colloids in sepsis [29], in 2013 the European Medicines Agency (EMA) banned their use for the treatment of septic and critically ill patients [30]. Of note, in a retrospective cohort study it was shown that the volume of crystalloids given for fluid resuscitation in critically ill patients was on average only 1.4 times higher than that of colloids [31]. Currently, the only indication for HES remains the treatment of hypovolemia due to acute blood loss when crystalloids alone are not considered sufficient [30].

Regarding the choice of which isotonic crystalloid should be administer-i.e., balanced crystalloids vs. normal saline solution-over the years no clear recommendations have been made. On the one hand, it has often been advocated that saline solution could exert detrimental effects on both renal function and the patient's ability to recover from severe illnesses, due to its large amount of chloride [32]. On the other hand, no study has been able to demonstrate a clear superiority of balanced crystalloids over saline solution in critically ill patients. In this regard, in non-critically ill patients treated in the ED with saline or balanced crystalloids, the SALT-ED study confirmed no differences in terms of in-hospital free days [33]. Nonetheless, the authors demonstrated a significant lower incidence of major kidney adverse events within 30 days in the balanced crystalloids group. In contrast, the SMART trial, which compared the efficacy of the two solutions in a cohort of 15,802 critically ill patients, reported a lower rate of the composite outcome of death from any cause, new renal-replacement therapy, or persistent renal dysfunction when balanced crystalloids were used [34]. The secondary analysis conducted on the subgroup of septic patients $(n=1641)$ also demonstrated a lower 30 day in-hospital mortality, as well as a lower incidence of major renal events and a higher number of vasopressorfree days when balanced crystalloids were given compared to normal saline. Therefore, even though no clear recommendations have been made from the Scientific Societies since then, the administration of Ringer Lactate solution in the resuscitation of septic shock patients may be considered appropriate. Although in the SMART trial [34] the septic subgroup was pre-specified, and the number of patients afforded a great statistical power, the results of the two ongoing PLUS (Plasma-Lyte 148 vs Saline) [35] and BaSICS (Balanced Solution vs Saline in Intensive Care) [36] studies are expected to confirm such findings.

Lastly, the use of a hypertonic solution in resuscitation of septic shock patients has been recently put into question following the premature stop of the HYPERS2S trial, evaluating both hyperoxia $v s$. normoxia and normal saline $v s$. hypertonic saline, due to increased mortality in both intervention groups [37]. Even though the rationale behind the administration of a hypertonic solution (i.e., $3 \% \mathrm{NaCl}$ ) to septic shock patients is that this treatment should exert a greater osmotic effect, such effect does not often last very long, making the hypertonic effect futile. In addition, 
it consists of the administration of a very large amount of chloride, which increases the risk of renal damage. For this reason, we believe that infusing septic shock patients with a hypertonic saline solution should not be recommended in the daily clinical practice.

\section{Vasopressors}

According to the Sepsis-3 definitions, septic shock patients can be clinically identified by the requirement of vasoactive medicaments (Fig. 1) [1]. In this regard, both the 2016 SSC guidelines and the 2018 SSC bundle recommend the early administration of vasopressors in hypotensive septic patients to revert the severely impaired arterial tone $[2,3]$.

\section{Norepinephrine}

Norepinephrine (NE) is recommended as the first-line vasoactive agent in the management of septic shock patients [2]. Its vasoconstrictive action is exerted through the stimulation of $\alpha 1$-adrenergic receptors, with little influence on the heart rate [38].

Over the years, there has been a growing consensus for the need of early NE administration in septic patients, supported by a series of validated reasons [39]. The first and most obvious one is that, by reversing hypotension or limiting its duration-prolonged hypotension is among the main determinants of mortality-patient outcome is improved. Another reason supporting early NE administration is that the stimulation of $\alpha 1$-receptors on the venous side triggers venous constriction and increases the amount of stressed blood volume [40]. This leads to enhanced venous return and improved cardiac preload. Of note, fluid administration under such conditions should be more efficient as it would be performed in a more pressurized venous system, thus acting on the stressed volume and, ultimately, reducing the amount of fluid given [41]. Lastly, the fact that in the initial phases of septic shock cardiac $\beta 1$-adrenergic receptors are still expressed on cardiac cells allows cardiac contractility to increase through NE administration [42]. This beneficial effect of NE is also promoted by a concomitant increase in diastolic arterial pressure, which is the perfusion pressure of the left ventricle coronary artery [42].

Different studies have evaluated the effects of early NE administration in septic shock patients. Two retrospective studies by Colon-Hidalgo [43] and Bai [44] have shown that the time to NE initiation is an independent predictor of mortality. In this regard the CENSER trial has directly compared early NE administration to NE administration only when fluid therapy has failed [45]. The results of this trial have shown that early NE administration is associated with increased shock control over the first $6 \mathrm{~h}$ (primary endpoint).
However, no significant differences in terms of mortality were observed (secondary endpoint), even though the early NE group had significant lower rates of cardiogenic pulmonary oedema and new-onset arrhythmias [45]. In this regard, a large ongoing randomized controlled trial (RCT) (the CLOVERS trial), specifically designed to evaluate the effects of early NE administration on 90-day mortality, is expected to provide more definitive results on this issue (ClinicalTrials.gov Identifier: NCT03434028).

However, the existing data, along with those of a recent meta-analysis showing a significant reduction in both shortterm mortality and the amount of fluid given, suggest that the early administration of NE is safe [46]. Thus, the emergency physician should be encouraged to start NE administration right from the initial phases of resuscitation, especially in case of concurrent tachycardia and low diastolic arterial pressure, which is a sign of strongly impaired arterial tone [47].

Once NE administration is started, the consensus is that its dosage should be titrated to obtain a MAP of $65 \mathrm{mmHg}$ [2]. It is not however clear whether higher values should be targeted. In this regard, the SEPSISPAM study, which compared $65 \mathrm{mmHg}$ vs. $85 \mathrm{mmHg}$ as MAP target, did not find significant differences in terms of mortality [48]. Nevertheless, when the subgroup of patients with a history of arterial hypertension was analysed, a higher MAP target exerted a beneficial effect on the renal function. Thus, a task force of the European Society of Intensive Care Medicine (ESICM) has recommended that a MAP value greater than $65 \mathrm{mmHg}$ should be the initial blood pressure target in septic shock patients with arterial hypertension [49]. When elevated doses of $\mathrm{NE}(\geq 1 \mu \mathrm{g} / \mathrm{Kg} / \mathrm{min})$ are required for refractory hypotension, the use a second vasopressor is advised.

\section{Other vasoactive agents}

Vasopressin is the vasoactive agent that the 2016 SSC guidelines suggest to add to NE in case of refractory shock [2] to reduce the amount of adrenergic tone and increase vasoconstriction through a different receptor stimulation. In this regard, one meta-analysis showed that when vasopressin was associated to NE, the rate of arrhythmic events, such as atrial fibrillation, was reduced compared to NE alone, but no differences on mortality were recorded [50]. It is however important to point out that vasopressin is not available in all countries.

Epinephrine is another second-line vasopressor recommended by the 2016 SSC, whose use should be considered in case of concurrent cardiac dysfunction [2]. However, according to the existing literature, no superiority in terms of patient survival was observed in patients treated with epinephrine alone compared to patients treated with a combination of NE and dobutamine. 
Dopamine, which was recommended by previous guidelines, should not be used in the management of septic patients as either vasopressor or, at low doses, renal protective agent [2]. It has been shown that its use is associated with an increased risk of cardiac arrhythmias and mortality, compared to NE [51]. Currently, its use is only recommended in case of bradycardia.

\section{Monitoring}

Despite its intrinsic limitations, physical examination is widely regarded as an essential tool for septic shock recognition and initial disease management, [52]. Likewise, basic monitoring, such as heart rate, peripheral oxygen saturation, urinary output, arterial blood pressure, and CVP, can provide important information on the hemodynamic status of septic shock patients. These easily obtainable variables allow the physician to not only detect rapid changes but also identify specific targets for resuscitation (e.g., MAP $\geq 65 \mathrm{mmHg}$ ) $[47,53]$.

In case of vasopressors administration, invasive arterial blood pressure monitoring is suggested, albeit neither arterial catheter nor central venous catheter (CVC) placement should delay NE administration. Under these conditions, vasopressor treatment can be initiated on a peripheral venous line with non-invasive BP monitoring, and it should be shifted, as soon as possible, to CVC administration accompanied by invasive arterial pressure monitoring $[41,54]$. As basic hemodynamic monitoring is not able to detect the effects of fluid challenge on $\mathrm{CO}[55,56]$, methods for continuous $\mathrm{CO}$ monitoring are recommended to track changes in $\mathrm{CO}$ both during tests of preload responsiveness $[22,57,58]$ and fluid challenge $[23,59]$.

\section{Minimally invasive and non-invasive monitoring methods}

Over the last two decades, the use of the pulmonary artery catheter has sharply declined, making transpulmonary thermodilution (TPTD) the new gold standard techniques for $\mathrm{CO}$ measurement. Through the injection of 3 boluses of cold saline in the CVC and the detection of changes in blood temperature by means of a femoral thermistor-tipped arterial catheter, the TPTD device can measure CO [60]. However, its use in septic patients is recommended in the presence of acute respiratory distress syndrome in the ICU rather than the ED [49, 61].

Thus, various non-invasive methods for $\mathrm{CO}$ monitoring have been developed over the years. Among them, the analysis of the arterial pulse wave contour, which is proportional to $\mathrm{CO}$, is a method that requires the placement of an arterial line with a dedicated catheter [62]. CO is estimated through proprietary algorithms at each cardiac beat, indexed to biometric parameters. However, since it does not have a calibrating system - conversely to TPTD devices-after some time from its placement, or in case of changes in vascular resistance, its measurements become less reliable [52].

Echocardiography is, on the other hand, a completely non-invasive and rapidly available tool at the bedside. $\mathrm{CO}$ can be assessed by evaluating relative changes in the velocity-time integral (VTI) of the left ventricular outflow tract [63]. This technique allows the evaluation of beat-to-beat changes in $\mathrm{CO}$ during both tests of preload responsiveness and fluid administration, with good accuracy and interobserver concordance [63]. Finally, in recent years different new techniques have been developed, improved, and validated for non-invasive $\mathrm{CO}$ monitoring, ranging from bioreactance [64] to plethysmography $[65,66]$, which may be optimal for the ED setting. It should be noticed that inferior vena cava variations must not be used to assess preload responsiveness or response to fluid administration in spontaneously breathing patients [67].

\section{Lactate and peripheral perfusion assessment}

According to the 2016 SSC guidelines, blood lactate normalization is one of the target of resuscitation in septic shock patients [2], supposing that high lactate levels reflect the degree of tissue hypoperfusion. However, the fact that lactate levels depend on the balance between lactate production and clearance may slow down the kinetics of blood lactate normalization in resuscitating patients. This could be further complicated by the possibility that hyperlactatemia may be related to causes other than hypoperfusion [68]. In this regard, capillary refill time (CRT), defined as the time taken for a distal capillary bed to regain its color after pressure has been applied to cause blanching, has emerged over the recent years as a tool for the assessment of peripheral tissue perfusion [69]. In 2019, the ANDROMEDA-SHOCK study [70] compared peripheral perfusion-targeted $v s$. lactatetargeted resuscitation in terms of mortality in 424 septic shock patients. Even though it failed to reach statistical significance $(p=0.06)$, the CRT-targeted strategy was associated to lower mortality at 28 days, which has been recently confirmed by several post-hoc analyses [71-73].

\section{Antimicrobial therapy}

Antimicrobial therapy, together with fluid resuscitation, is the cornerstone of septic patients treatment [2,3]. Provided that it does not determine substantial delays in the initiation of the treatment, antibiotic administration should be preceded by appropriate routine microbiological cultures [2]. According to guidelines, two sets of blood cultures must 
always be collected, notably one for aerobics and one for anaerobics.

\section{When should the antimicrobial therapy be started?}

The 2016 SSC guidelines recommend that intravenous antibiotic administration should begin within one hour after sepsis and septic shock recognition [2]. In this regard, many studies have highlighted the detrimental role of late antibiotic administration in septic patients [74-77]. Among the most recent ones, Liu et al. [78] performed a retrospective analysis of 35,000 septic patients from $21 \mathrm{ED}$ in the US, for whom antibiotic therapy was administered within $6 \mathrm{~h}$ of arrival. In their analysis, they demonstrated that a delay in antibiotic administration significantly increased the adjusted in-hospital mortality with an odds ratio (OR) of 1.09 (1.05-1.13) for each hour of delay. In the unadjusted analysis, the subgroup of septic shock patients emerged to be the one in which such effect was more pronounced [78]. Similarly, on a retrospective analysis of 40,696 septic and septic shock patients, Seymour et al. [79] demonstrated that an increased time to antibiotic administration was associated with a higher risk-adjusted in-hospital mortality [OR 1.04 (1.03-1.06) per hour]. More recently, Kashouris et al. evaluated the impact of the time between prescription and antimicrobial administration on the mortality rate among a cohort of 4429 septic patients. The authors showed that the OR for 28 day mortality increased when antimicrobial therapy was administered beyond $1 \mathrm{~h}$, reaching a median value of $1.85(1.29-2.65)$ if the delay was more than $12 \mathrm{~h}$ [80]. Likewise, a retrospective analysis of 10,811 ED septic patients showed that each additional hour from ED arrival to antibiotic initiation increased the odds of 1 year [1.10 (1.05-1.14)], in-hospital [1.16 (1.07-1.26)], 30 day [1.12 (1.06-1.18)] and 90 day [1.09 (1.04-1.15)] mortality [81].

\section{What antimicrobial therapy should I start with?}

As the time to the first dose of antibiotic is crucial, an empiric broad-spectrum antimicrobial therapy must be initiated as soon as possible, until the underlying pathogen is recognized and antimicrobial sensitivities are established [2]. In this regard, the initial choice should consider different issues, such as the primary site of infection, the prevalent pathogens and antimicrobial resistances in that geographical area, and the patient's age and comorbidities. However, due to the variety of such conditions in the population of septic patients, the 2016 SSC could not issue specific therapeutic regimens, but rather a series of suggestions [2].

Thus, as most of the septic shock patients exhibit a various degree of immunosuppression, the initial treatment should target pathogens frequently encountered in healthcare-associated infections, notably Gram-negative pathogens. The SSC guidelines suggest initiating with either a broad-spectrum carbapenem (e.g., meropenem, imipenem/ cilastatin) or an extended-range penicillin/ $\beta$-lactamase inhibitor (e.g., piperacillin/tazobactam, ticarcillin/clavulanate), even though third or higher-generation cephalosporins may also be used. However, to be more effective, the SSC guidelines adopt the concept of "multidrug therapy", suggesting that a combination of multiple antimicrobials may be more effective for broad spectrum coverage [2]. As a matter of fact, in critically ill patients at high risk of infection from multidrug-resistant pathogens, it is recommended to add a supplemental Gram-negative agent (e.g., aminoglycoside, fluoroquinolone) to improve the probability of having at least one efficient antibiotic [82]. Similarly, in case of suspected MRSA-related sepsis, it is recommended to add either vancomycin, teicoplanin, or another anti-MRSA agent. Again, in the presence of patients at high risk for invasive Candida infection, the empiric addition of an echinocandin (e.g., caspofungin, anidulafungin, and micafungin) is regarded as a reasonable choice [2]. In case of doubts, the clinician should seek consultation with an infectious disease specialist.

Once the pathogen has been identified and antimicrobial sensitivities have been determined, the broad-spectrum treatment should be discontinued and a targeted/definitive therapy, either mono- or combination, initiated [2, 82].

\section{What antimicrobial dose should be used in the ED?}

The emergency physician should always bear in mind the hemodynamic alterations of septic shock when prescribing the first administration of antibiotic, since recommended doses are often inadequate to reach the therapeutic target. As a matter of fact, the increased capillary permeability, the hyperdynamic state, and the large amount of fluid administered may all contribute to increase the volume of distribution of the medication, especially for hydrophilic antibiotics (e.g., $\beta$-lactams, aminoglycosides, glycopeptides) [83]. Similarly, for highly protein-bound antimicrobials, such as, ceftriaxone, ertapenem, daptomycin, and teicoplanin, the presence of hypoalbuminemia may augment the unbound fraction, increasing the volume of distribution and the risk of early renal clearance [84]. For these reasons, it is recommended to increase the loading dose of roughly 1.5 times the standard dose $[13,85,86]$. However, to optimize the efficacy of antimicrobial therapy, also the pharmacokinetic/pharmacodynamic (PK-PD) index for each class of antibiotic should be taken into account, especially for maintenance doses (e.g., shortening dosing intervals, continuous infusions, etc.) [87, 88] (Table 1). Nevertheless, even in this 
Table 1 Pharmacokinetic/Pharmacodynamic indices of different antimicrobial classes and suggestions for dose adjustment in critically ill patients

\begin{tabular}{|c|c|c|c|c|}
\hline Antimicrobial class & PK/PD index & $\begin{array}{l}\text { Clinical PK/PD target for } \\
\text { efficacy }\end{array}$ & $\begin{array}{l}\text { Clinical PK/ } \\
\text { PD threshold for } \\
\text { toxicity }\end{array}$ & $\begin{array}{l}\text { Adjustment in critically ill } \\
\text { patients }\end{array}$ \\
\hline Aminoglycosides & $\mathrm{AUC}_{0-24} / \mathrm{MIC}$ and $\mathrm{C}_{\max } / \mathrm{MIC}$ & & & $\begin{array}{l}\text { High, single dose and extended } \\
\text { interval dosing }\end{array}$ \\
\hline Amikacin & & $\mathrm{C}_{\max } / \mathrm{MIC} \geq 8-10$ & $\mathrm{C}_{\min }>5 \mathrm{mg} / \mathrm{L}$ & \\
\hline Gentamicin/Tobramycin & & $\begin{array}{l}\mathrm{AUC}_{0-24} / \mathrm{MIC} \geq 110 \\
\mathrm{C}_{\max } / \mathrm{MIC} \geq 8-10\end{array}$ & $\mathrm{C}_{\min }>1 \mathrm{mg} / \mathrm{L}$ & \\
\hline Beta-lactams & $\% \mathrm{fT}_{>\mathrm{MIC}}$ & & & Initial loading dose, followed \\
\hline Carbapenems & & $50-100 \% \mathrm{fT}_{>\mathrm{MIC}}$ & $\mathrm{C}_{\min }>44.5 \mathrm{mg} / \mathrm{L}$ & by prolonged (continuous or \\
\hline Cephalosporin & & $45-100 \% \mathrm{fT}_{>\mathrm{MIC}}$ & $\mathrm{C}_{\min }>20 \mathrm{mg} / \mathrm{L}$ & \\
\hline Penicillins & & $50-100 \% \mathrm{fT}_{>\mathrm{MIC}}$ & $\mathrm{C}_{\min }>361 \mathrm{mg} / \mathrm{L}$ & \\
\hline Daptomycin & $\mathrm{AUC}_{0-24} / \mathrm{MIC}$ & $\mathrm{AUC}_{0-24} / \mathrm{MIC} \geq 666 \mathrm{mg} / \mathrm{L}$ & $\mathrm{C}_{\min }>24 \mathrm{mg} / \mathrm{L}$ & $\begin{array}{l}\text { Higher doses }(10-12 \mathrm{mg} / \\
\mathrm{kg} / \text { day }) \text { to increase MIC } \\
(>0.1 \mathrm{mg} / \mathrm{L})\end{array}$ \\
\hline Fluoroquinolones & $\mathrm{AUC}_{0-24} / \mathrm{MIC}$ and $\mathrm{C}_{\max } / \mathrm{MIC}$ & $\begin{array}{l}\mathrm{AUC}_{0-24} / \mathrm{MIC} \geq 125-250 \\
\mathrm{C}_{\max } / \mathrm{MIC} \geq 12\end{array}$ & Unclear & $\begin{array}{l}\text { Loading dose with higher } \\
\text { maintenance doses should be } \\
\text { considered }\end{array}$ \\
\hline Glycopeptides & $\mathrm{AUC}_{0-24} / \mathrm{MIC}$ & & & \\
\hline Teicoplanin & & $\mathrm{C}_{\min } \geq 10 \mathrm{mg} / \mathrm{L}$ & Unclear & $\begin{array}{l}\text { Loading dose essential to } \\
\text { reduce time to reach therapeu- } \\
\text { tic exposures }\end{array}$ \\
\hline Vancomycin & & $\begin{array}{l}\mathrm{AUC}_{0-24} / \mathrm{MIC} \geq 400 \\
\mathrm{C}_{\min }>10-20 \mathrm{mg} / \mathrm{L}\end{array}$ & $\begin{array}{l}\mathrm{AUC}_{0-24}>700 \\
\mathrm{C}_{\min }>20 \mathrm{mg} / \mathrm{L}\end{array}$ & $\begin{array}{l}\text { Consider loading dose of } \\
25-30 \mathrm{mg} / \mathrm{kg} \text {, followed by } \\
15-20 \mathrm{mg} / \mathrm{kg} \text { every } 8-12 \mathrm{~h} \text { if } \\
\text { MIC }>1 \mathrm{mg} / \mathrm{L} \text { and no renal } \\
\text { impairment }\end{array}$ \\
\hline Linezolid & & $\begin{array}{l}\mathrm{AUC}_{0-24} / \mathrm{MIC} 80-120 \\
\geq 85 \% \mathrm{~T}_{>\mathrm{MIC}}\end{array}$ & $\begin{array}{l}\mathrm{AUC}_{0-24}>300-350 \\
\mathrm{C}_{\min }>7-10\end{array}$ & $\begin{array}{l}\text { Higher doses can be considered } \\
\text { in ARDS and obese patients, } \\
\text { or if MIC } \geq 2 \mathrm{mg} / \mathrm{L}\end{array}$ \\
\hline Echinocandins & $\mathrm{AUC}_{0-24} / \mathrm{MIC}$ & $\mathrm{AUC}_{0-24} / \mathrm{MIC} \geq 3000$ & No data & $\begin{array}{l}\text { Higher body weight may } \\
\text { require higher dosing }\end{array}$ \\
\hline Fluconazole & $\mathrm{AUC}_{0-24} / \mathrm{MIC}$ & $\mathrm{AUC}_{0-24} / \mathrm{MIC} \geq 55-100$ & Unclear & $\begin{array}{l}\text { Loading dose of } 12 \mathrm{mg} / \mathrm{kg} \mathrm{IV} \text {, } \\
\text { followed by } 6-12 \mathrm{mg} / \mathrm{kg} / \text { day } \\
\text { to reach therapeutic targets } \\
\left.\text { ( } \mathrm{AUC}_{0-24} / \mathrm{MIC} 25-100\right) \text {, if no } \\
\text { renal impairment }\end{array}$ \\
\hline Voriconazole & $\mathrm{AUC}_{0-24} / \mathrm{MIC}$ & $\mathrm{C}_{\min } \geq 1-2 \mathrm{mg} / \mathrm{L}$ & $\mathrm{C}_{\min } \geq 4.5-6 \mathrm{mg} / \mathrm{L}$ & $\begin{array}{l}\text { Loading dose of } 6 \mathrm{mg} / \mathrm{kg} \mathrm{IV} \\
\text { every } 12 \mathrm{~h} \text { for two doses, } \\
\text { followed by } 3-4 \mathrm{mg} / \mathrm{kg} \mathrm{IV} \\
\text { every } 12 \mathrm{~h}\end{array}$ \\
\hline
\end{tabular}

Adapted from [89]

$A U C_{0-24} / M I C$ ratio of the area under the concentration-time curve over a $24 \mathrm{~h}$ period to minimum inhibitory concentration, $C_{m a x} / M I C$ ratio of the maximum drug concentration to minimum inhibitory concentration, $C_{\min }$ minimum drug concentration, $f T_{>M I C}$ duration of time that the free drug concentration remains above the minimum inhibitory concentration during a dosing interval, $I V$ intravenously, $M I C$ minimum inhibitory concentration, $P K / P D$ pharmacokinetic/pharmacodynamic

case, due to the pathophysiological complexity of the septic shock it is difficult to predict the response to an antimicrobial regimen. Therefore, the implementation of antimicrobial therapeutic drug monitoring has been suggested as standard of care in septic shock patients treated with different types of antibiotics [89].

\section{Adjunctive therapy}

\section{Steroids}

The presence of a relative adrenal insufficiency is the main rationale for the administration of low-dose steroids in 
septic shock patients [90]. In theory, steroids are expected to improve the cardiovascular function by not just restoring the blood volume through mineralocorticoid activity but also increasing the systemic vascular resistance, which is partially mediated by glucocorticoid receptors [91]. In 2008, the CORTICUS trial evaluated the effects of IV administration of $50 \mathrm{mg}$ hydrocortisone every $6 \mathrm{~h}$ for five days, compared to placebo, in 499 septic shock patients [92]. The results of this large multicenter RCT showed no difference in terms of 28-day mortality between patients who did not have an appropriate response to a corticotropin test (primary outcome) and patients who instead were responsive to such test [92]. It was however observed a quicker reversal of shock in the hydrocortisone group, together with increased risk of developing superinfections. Since then, controversial results have been reported by different reviews and meta-analyses. Among them, Annane et al. [93], analyzing 12 clinical trials, showed that prolonged low-dose corticosteroid therapy reduced 28-day mortality, whereas Sligl et al. [94] and Volbeda et al. [95] could not reach the same conclusions examining 8 and 35 trials, respectively. Thus, both the 2012 and 2016 SSC guidelines have recommended the use of low-dose corticosteroids (notably hydrocortisone $200 \mathrm{mg}$ IV once a day) only in patients with severe shock, unresponsive to fluids and vasopressors $[2,96]$.

In 2018, the results from two large RCTs were published, namely ADRENAL and APROCCHSS [91, 97]. The former enrolled 3658 patients with septic shock under mechanical ventilation and measured as primary outcome the differences in mortality at 90 days between patients treated with hydrocortisone $200 \mathrm{mg}$ IV once a day for seven days and the placebo group. Even though the results showed a faster resolution of shock, fewer days on mechanical ventilation, and shorter ICU length of stay in the hydrocortisone group, no differences were observed in terms of 90-day mortality [97]. On the other hand, the APROCCHSS trial [91] enrolled 1241 septic shock patients in whom clinical conditions did not improve after initial resuscitation, according to the $6 \mathrm{~h}$ bundle of the 2008 SSC [98]. Patients were randomly assigned to receive either hydrocortisone (50 mg IV every $6 \mathrm{~h}$ ) plus fludrocortisone (50 $\mu \mathrm{g}$ tablet once/day) for seven days without tapering, or placebo. Compared to the placebo group, the hydrocortisone plus fludrocortisone-treated group displayed a substantial decrease in mortality at 90 (primary outcome) and 180 days, as well as a significant increase in the number of vasopressor- and organ failure-free days. The authors stated that fludrocortisone had been added to hydrocortisone to provide additional mineralocorticoid potency, following the assumption that the increased mineralocorticoid activity would have counteracted
NF- $\mathrm{BB}$-mediated downregulation of vascular mineralocorticoid receptors, further improving the cardiovascular function [91]. As the systematic reviews and meta-analyses including these two large trials provided once again conflicting results $[99,100]$, the recommendations issued by the 2016 SSC on this issue still hold true [2].

\section{Ascorbic acid and thiamine}

The therapeutic role of vitamin $\mathrm{C}$ in septic patients has been proposed by Marik et al. in a small-size retrospective study, where it was shown that intravenous administration of this vitamin in combination with thiamine and hydrocortisone (HAT therapy) reduced both mortality and organ failure in sepsis and septic shock patients [101]. This improved patient outcome could be the result of the synergistic and overlapping actions on different components of the host immune response to infection, such as restoration of the dysregulated immune system [102]. Since then, different small-size RCTs have investigated the efficacy of HAT therapy in sepsis and septic shock patients [103-106] with discordant results. In this regard, a meta-analysis by Rui Shi et al. [107] did not report a clear benefit on mortality in HAT-treated patients, whereas it was recorded a significant reduction in vasopressor administration frequency as well as a decreased SOFA score [107]. The results of the ongoing VICTAS Trial [108], which is expected to enroll 2000 septic patients, may lead to more robust conclusions.

\section{Conclusions}

Patients with severe sepsis and/or septic shock are at increased risk of death and organ dysfunction and display high in-hospital mortality. Since the last SSC guidelines were issued, a number of studies have provided new information on the pathophysiology and treatment of septic shock. Despite this growing knowledge, septic shock management remains a challenging task for the emergency physicians, who have to deal with the initial detection of the condition and the early phases of treatment. Thus, it is of utmost importance that emergency physicians be aware of the recent advances on septic patient management.

In light of the above considerations, this narrative review provides a useful and updated learning tool that should enable emergency physicians to gather crucial information on past, present, and future research trajectories of sepsis research.

Overall, we believe that a systematic approach consisting of coordinated detection of patients with sepsis and early treatment could significantly reduce the mortality of septic 
patients in the ED. To further optimize disease management, the emergency physician should administer treatment taking into account the patients' characteristics.

Author contributions The three authors equally contributed to writing the manuscript.

Funding Open access funding provided by Università degli Studi del Piemonte Orientale Amedeo Avogrado within the CRUI-CARE Agreement.

\section{Declarations}

Conflict of interest All the authors declare they do not have any conflict of interest.

Human and animal rights Not applicable.

Informed consent Not applicable.

Open Access This article is licensed under a Creative Commons Attribution 4.0 International License, which permits use, sharing, adaptation, distribution and reproduction in any medium or format, as long as you give appropriate credit to the original author(s) and the source, provide a link to the Creative Commons licence, and indicate if changes were made. The images or other third party material in this article are included in the article's Creative Commons licence, unless indicated otherwise in a credit line to the material. If material is not included in the article's Creative Commons licence and your intended use is not permitted by statutory regulation or exceeds the permitted use, you will need to obtain permission directly from the copyright holder. To view a copy of this licence, visit http://creativecommons.org/licenses/by/4.0/.

\section{References}

1. Singer M, Deutschman CS, Seymour CW et al (2016) The third international consensus definitions for sepsis and septic shock (sepsis-3). JAMA 315:801-810. https://doi.org/10.1001/jama. 2016.0287

2. Rhodes A, Evans LE, Alhazzani W et al (2017) Surviving sepsis campaign: international guidelines for management of sepsis and septic shock: 2016. Crit Care Med 45:486-552. https://doi.org/ 10.1097/CCM.0000000000002255

3. Levy MM, Evans LE, Rhodes A (2018) The surviving sepsis campaign bundle: 2018 update. Crit Care Med 46:997-1000. https://doi.org/10.1097/CCM.0000000000003119

4. Sivayoham N, Blake LA, Tharimoopantavida SE et al (2020) Treatment variables associated with outcome in emergency department patients with suspected sepsis. Ann Intensive Care 10:136. https://doi.org/10.1186/s13613-020-00747-8

5. Loritz M, Busch H-J, Helbing T, Fink K (2020) Prospective evaluation of the quickSOFA score as a screening for sepsis in the emergency department. Intern Emerg Med 15:685-693. https:// doi.org/10.1007/s11739-019-02258-2

6. Crouser ED, Parrillo JE, Seymour CW et al (2019) Monocyte distribution width: a novel indicator of sepsis-2 and sepsis-3 in high-risk emergency department patients. Crit Care Med 47:1018-1025. https://doi.org/10.1097/CCM.0000000000 003799
7. Castello LM, Baldrighi M, Molinari L et al (2019) The role of osteopontin as a diagnostic and prognostic biomarker in sepsis and septic shock. Cells. https://doi.org/10.3390/cells8020174

8. Lundberg OHM, Lengquist M, Spångfors M et al (2020) Circulating bioactive adrenomedullin as a marker of sepsis, septic shock and critical illness. Crit Care 24:636. https://doi.org/10.1186/ s13054-020-03351-1

9. Castello LM, Gavelli F, Baldrighi M et al (2020) Hypernatremia and moderate-to-severe hyponatremia are independent predictors of mortality in septic patients at emergency department presentation: a sub-group analysis of the need-speed trial. Eur J Intern Med. https://doi.org/10.1016/j.ejim.2020.10.003

10. Mearelli F, Fiotti N, Giansante C et al (2018) Derivation and validation of a biomarker-based clinical algorithm to rule out sepsis from noninfectious systemic inflammatory response syndrome at emergency department admission: a multicenter prospective study. Crit Care Med 46:1421-1429. https://doi. org/10.1097/CCM.0000000000003206

11. Vincent J-L, Jones G, David S et al (2019) Frequency and mortality of septic shock in Europe and North America: a systematic review and meta-analysis. Crit Care 23:196. https:// doi.org/10.1186/s13054-019-2478-6

12. Vincent J-L, De Backer D (2004) Oxygen transport-the oxygen delivery controversy. Intensive Care Med 30:1990-1996. https://doi.org/10.1007/s00134-004-2384-4

13. De Backer D, Cecconi M, Lipman J et al (2019) Challenges in the management of septic shock: a narrative review. Intensive Care Med 45:420-433. https://doi.org/10.1007/ s00134-019-05544-X

14. Monnet X, Teboul J-L (2018) My patient has received fluid. How to assess its efficacy and side effects? Ann Intensive Care 8:54. https://doi.org/10.1186/s13613-018-0400-z

15. De Backer D, Vincent J-L (2018) Should we measure the central venous pressure to guide fluid management? Ten answers to 10 questions. Crit Care 22:43. https://doi.org/10.1186/ s13054-018-1959-3

16. Augusto J-F, Teboul J-L, Radermacher P, Asfar P (2011) Interpretation of blood pressure signal: physiological bases, clinical relevance, and objectives during shock states. Intensive Care Med 37:411-419. https://doi.org/10.1007/s00134-010-2092-1

17. Annane D, Bellissant E, Cavaillon J-M (2005) Septic shock. Lancet 365:63-78. https://doi.org/10.1016/S0140-6736(04) 17667-8

18. Aneman A, Vieillard-Baron A (2016) Cardiac dysfunction in sepsis. Intensive Care Med 42:2073-2076. https://doi.org/10. 1007/s00134-016-4503-4

19. van Beest PA, Hofstra JJ, Schultz MJ et al (2008) The incidence of low venous oxygen saturation on admission to the intensive care unit: a multi-center observational study in The Netherlands. Crit Care 12:R33. https://doi.org/10.1186/cc6811

20. Ince C, Boerma EC, Cecconi M et al (2018) Second consensus on the assessment of sublingual microcirculation in critically ill patients: results from a task force of the European society of intensive care medicine. Intensive Care Med 44:281-299. https:// doi.org/10.1007/s00134-018-5070-7

21. Sessler CN, Shepherd W (2002) New concepts in sepsis. Curr Opin Crit Care 8:465-472. https://doi.org/10.1097/00075198200210000-00016

22. Monnet X, Teboul J-L (2015) Passive leg raising: five rules, not a drop of fluid! Crit Care 19:18. https://doi.org/10.1186/ s13054-014-0708-5

23. Monnet X, Teboul J-L (2018) Cardiac output monitoring: throw it out... or keep it? Crit Care 22:35. https://doi.org/10.1186/ s13054-018-1957-5 
24. Monnet X, Teboul J-L (2020) Prediction of fluid responsiveness in spontaneously breathing patients. Ann Transl Med 8:790. https://doi.org/10.21037/atm-2020-hdm-18

25. Jozwiak M, Hamzaoui O, Monnet X, Teboul J-L (2018) Fluid resuscitation during early sepsis: a need for individualization. Minerva Anestesiol 84:987-992. https://doi.org/10.23736/ S0375-9393.18.12422-9

26. Bayer O, Reinhart K, Kohl M et al (2012) Effects of fluid resuscitation with synthetic colloids or crystalloids alone on shock reversal, fluid balance, and patient outcomes in patients with severe sepsis: a prospective sequential analysis. Crit Care Med 40:2543-2551. https://doi.org/10.1097/CCM.0b013e318258fee7

27. Perner A, Haase N, Guttormsen AB et al (2012) Hydroxyethyl starch 130/0.42 versus Ringer's acetate in severe sepsis. N Engl J Med 367:124-134. https://doi.org/10.1056/NEJMoa1204242

28. Brunkhorst FM, Engel C, Bloos F et al (2008) Intensive insulin therapy and pentastarch resuscitation in severe sepsis. N Engl $\mathrm{J}$ Med 358:125-139. https://doi.org/10.1056/NEJMoa070716

29. Hemmings HC, Shafer SL (2020) Further retractions of articles by Joachim Boldt. Br J Anaesth 125:409-411. https://doi.org/ 10.1016/j.bja.2020.02.024

30. Europena Medicines Agency (2018) Hydroxyethyl-starch solutions (HES) should no longer be used in patients with sepsis or burn injuries critically ill-CMDh endorses PRAC recommendations. https://www.ema.europa.eu/en/news/hydroxyeth yl-starch-solutions-hes-should-no-longer-be-used-patientssepsis-burn-injuries-critically. Accessed 5 Dec 2020

31. Schortgen F, Brochard L (2012) Withdrawing synthetic colloids in sepsis is possible and safe. Crit Care Med 40:27092710. https://doi.org/10.1097/CCM.0b013e31825f6d07

32. Suetrong B, Pisitsak C, Boyd JH et al (2016) Hyperchloremia and moderate increase in serum chloride are associated with acute kidney injury in severe sepsis and septic shock patients. Crit Care 20:315. https://doi.org/10.1186/s13054-016-1499-7

33. Self WH, Semler MW, Wanderer JP et al (2018) Balanced crystalloids versus saline in noncritically ill adults. N Engl J Med 378:819-828. https://doi.org/10.1056/NEJMoa1711586

34. Semler MW, Self WH, Wanderer JP et al (2018) Balanced crystalloids versus saline in critically ill adults. N Engl J Med 378:829-839. https://doi.org/10.1056/NEJMoa1711584

35. Hammond NE, Bellomo R, Gallagher M et al (2017) The plasma-lyte $148 \mathrm{v}$ saline (PLUS) study protocol: a multicentre, randomised controlled trial of the effect of intensive care fluid therapy on mortality. Crit Care Resusc 19:239-246

36. Zampieri FG, Azevedo LCP, Corrêa TD et al (2017) Study protocol for the balanced solution versus saline in intensive care study (BaSICS): a factorial randomised trial. Crit Care Resusc 19:175-182

37. Asfar P, Schortgen F, Boisramé-Helms J et al (2017) Hyperoxia and hypertonic saline in patients with septic shock (HYPERS2S): a two-by-two factorial, multicentre, randomised, clinical trial. Lancet Respir Med 5:180-190. https://doi.org/10. 1016/S2213-2600(17)30046-2

38. Shi R, Hamzaoui O, De Vita N et al (2020) Vasopressors in septic shock: which, when, and how much? Ann Transl Med 8:794. https://doi.org/10.21037/atm.2020.04.24

39. Scheeren TWL, Bakker J, De Backer D et al (2019) Current use of vasopressors in septic shock. Ann Intensive Care 9:20. https://doi.org/10.1186/s13613-019-0498-7

40. Hernández G, Teboul J-L, Bakker J (2019) Norepinephrine in septic shock. Intensive Care Med 45:687-689. https://doi.org/ 10.1007/s00134-018-5499-8

41. Ospina-Tascón GA, Hernandez G, Alvarez I et al (2020) Effects of very early start of norepinephrine in patients with septic shock: a propensity score-based analysis. Crit Care 24:52. https://doi.org/10.1186/s13054-020-2756-3
42. Hamzaoui O, Jozwiak M, Geffriaud T et al (2018) Norepinephrine exerts an inotropic effect during the early phase of human septic shock. Br J Anaesth 120:517-524. https://doi.org/10. 1016/j.bja.2017.11.065

43. Colon Hidalgo D, Patel J, Masic D et al (2020) Delayed vasopressor initiation is associated with increased mortality in patients with septic shock. J Crit Care 55:145-148. https:// doi.org/10.1016/j.jcrc.2019.11.004

44. Bai X, Yu W, Ji W et al (2014) Early versus delayed administration of norepinephrine in patients with septic shock. Crit Care 18:532. https://doi.org/10.1186/s13054-014-0532-y

45. Permpikul C, Tongyoo S, Viarasilpa T et al (2019) Early use of norepinephrine in septic shock resuscitation (CENSER). A randomized trial. Am J Respir Crit Care Med 199:1097-1105. https://doi.org/10.1164/rccm.201806-1034OC

46. Li Y, Li H, Zhang D (2020) Timing of norepinephrine initiation in patients with septic shock: a systematic review and meta-analysis. Crit Care 24:488. https://doi.org/10.1186/ s13054-020-03204-x

47. Magder S (2018) The meaning of blood pressure. Crit Care 22:257. https://doi.org/10.1186/s13054-018-2171-1

48. Asfar P, Meziani F, Hamel J-F et al (2014) High versus low blood-pressure target in patients with septic shock. N Engl J Med 370:1583-1593. https://doi.org/10.1056/NEJMoa1312173

49. Cecconi M, De Backer D, Antonelli M et al (2014) Consensus on circulatory shock and hemodynamic monitoring. Task force of the European society of intensive care medicine. Intensive Care Med 40:1795-1815. https://doi.org/10.1007/s00134-014-3525-Z

50. Nagendran M, Russell JA, Walley KR et al (2019) Vasopressin in septic shock: an individual patient data meta-analysis of randomised controlled trials. Intensive Care Med 45:844-855. https://doi.org/10.1007/s00134-019-05620-2

51. De Backer D, Aldecoa C, Njimi H, Vincent J-L (2012) Dopamine versus norepinephrine in the treatment of septic shock: a metaanalysis*. Crit Care Med 40:725-730. https://doi.org/10.1097/ CCM.0b013e31823778ee

52. Teboul J-L, Saugel B, Cecconi M et al (2016) Less invasive hemodynamic monitoring in critically ill patients. Intensive Care Med 42:1350-1359. https://doi.org/10.1007/s00134-016-4375-7

53. Chen H, Zhu Z, Zhao C et al (2020) Central venous pressure measurement is associated with improved outcomes in septic patients: an analysis of the MIMIC-III database. Crit Care 24:433. https://doi.org/10.1186/s13054-020-03109-9

54. Saugel B, Kouz K, Meidert AS et al (2020) How to measure blood pressure using an arterial catheter: a systematic 5-step approach. Crit Care 24:172. https://doi.org/10.1186/ s13054-020-02859-w

55. Ait-Hamou Z, Teboul J-L, Anguel N, Monnet X (2019) How to detect a positive response to a fluid bolus when cardiac output is not measured? Ann Intensive Care 9:138. https://doi.org/10. 1186/s13613-019-0612-x

56. Cecconi M, Hernandez G, Dunser M et al (2019) Fluid administration for acute circulatory dysfunction using basic monitoring: narrative review and expert panel recommendations from an ESICM task force. Intensive Care Med 45:21-32. https://doi.org/ 10.1007/s00134-018-5415-2

57. Gavelli F, Teboul J-L, Monnet X (2019) The end-expiratory occlusion test: please, let me hold your breath! Crit Care 23:274. https://doi.org/10.1186/s13054-019-2554-y

58. Taccheri T, Gavelli F, Teboul J-L et al (2021) Do changes in pulse pressure variation and inferior vena cava distensibility during passive leg raising and tidal volume challenge detect preload responsiveness in case of low tidal volume ventilation? Crit Care 25:110. https://doi.org/10.1186/s13054-021-03515-7

59. Dubin A, Loudet C, Kanoore Edul VS et al (2020) Characteristics of resuscitation, and association between use of dynamic tests of 
fluid responsiveness and outcomes in septic patients: results of a multicenter prospective cohort study in Argentina. Ann Intensive Care 10:40. https://doi.org/10.1186/s13613-020-00659-7

60. Monnet X, Teboul J-L (2017) Transpulmonary thermodilution: advantages and limits. Crit Care 21:147. https://doi.org/10.1186/ s13054-017-1739-5

61. Gavelli F, Teboul J-L, Azzolina D et al (2020) Transpulmonary thermodilution detects rapid and reversible increases in lung water induced by positive end-expiratory pressure in acute respiratory distress syndrome. Ann Intensive Care 10:28. https:// doi.org/10.1186/s13613-020-0644-2

62. de Courson H, Ferrer L, Cane G et al (2019) Evaluation of least significant changes of pulse contour analysis-derived parameters. Ann Intensive Care 9:116. https://doi.org/10.1186/ s13613-019-0590-z

63. Jozwiak M, Mercado P, Teboul J-L et al (2019) What is the lowest change in cardiac output that transthoracic echocardiography can detect? Crit Care 23:116. https://doi.org/10.1186/ s13054-019-2413-x

64. Galarza L, Mercado P, Teboul J-L et al (2018) Estimating the rapid haemodynamic effects of passive leg raising in critically ill patients using bioreactance. Br J Anaesth 121:567-573. https://doi.org/10.1016/j.bja.2018.03.013

65. Beurton A, Teboul J-L, Gavelli F et al (2019) The effects of passive leg raising may be detected by the plethysmographic oxygen saturation signal in critically ill patients. Crit Care 23:19. https://doi.org/10.1186/s13054-019-2306-z

66. Beurton A, Gavelli F, Teboul J-L et al (2021) Changes in the plethysmographic perfusion index during an end-expiratory occlusion detect a positive passive leg raising test. Crit Care Med 49:e151-e160. https://doi.org/10.1097/CCM.0000000000 004768

67. Das SK, Choupoo NS, Pradhan D et al (2018) Diagnostic accuracy of inferior vena caval respiratory variation in detecting fluid unresponsiveness: a systematic review and meta-analysis. Eur J Anaesthesiol 35:831-839. https://doi.org/10.1097/EJA.00000 00000000841

68. Castro R, Kattan E, Ferri G et al (2020) Effects of capillary refill time-vs. lactate-targeted fluid resuscitation on regional, microcirculatory and hypoxia-related perfusion parameters in septic shock: a randomized controlled trial. Ann Intensive Care 10:150. https://doi.org/10.1186/s13613-020-00767-4

69. Jacquet-Lagrèze $\mathrm{M}$, Bouhamri N, Portran P et al (2019) Capillary refill time variation induced by passive leg raising predicts capillary refill time response to volume expansion. Crit Care 23:281. https://doi.org/10.1186/s13054-019-2560-0

70. Hernández G, Ospina-Tascón GA, Damiani LP et al (2019) Effect of a resuscitation strategy targeting peripheral perfusion status vs serum lactate levels on 28 day mortality among patients with septic shock: the ANDROMEDA-SHOCK randomized clinical trial. JAMA 321:654-664. https://doi.org/10.1001/jama.2019. 0071

71. Kattan E, Hernández G, Ospina-Tascón G et al (2020) A lactatetargeted resuscitation strategy may be associated with higher mortality in patients with septic shock and normal capillary refill time: a post hoc analysis of the ANDROMEDA-SHOCK study. Ann Intensive Care 10:114. https://doi.org/10.1186/ s13613-020-00732-1

72. Zampieri FG, Damiani LP, Bakker J et al (2020) Effects of a resuscitation strategy targeting peripheral perfusion status versus serum lactate levels among patients with septic shock. A bayesian reanalysis of the ANDROMEDA-SHOCK trial. Am J Respir Crit Care Med 201:423-429. https://doi.org/10.1164/ rccm.201905-09680C

73. Kattan E, Ospina-Tascón GA, Teboul J-L et al (2020) Systematic assessment of fluid responsiveness during early septic shock resuscitation: secondary analysis of the ANDROMEDA-SHOCK trial. Crit Care 24:23. https://doi.org/10.1186/s13054-020-2732-y

74. Whiles BB, Deis AS, Simpson SQ (2017) Increased time to initial antimicrobial administration is associated with progression to septic shock in severe sepsis patients. Crit Care Med 45:623-629. https://doi.org/10.1097/CCM.0000000000002262

75. Peltan ID, Mitchell KH, Rudd KE et al (2017) Physician variation in time to antimicrobial treatment for septic patients presenting to the emergency department. Crit Care Med 45:1011-1018. https:// doi.org/10.1097/CCM.0000000000002436

76. Marik PE, Farkas JD (2018) The changing paradigm of sepsis: early diagnosis, early antibiotics, early pressors, and early adjuvant treatment. Crit Care Med 46:1690-1692. https://doi.org/10. 1097/CCM.0000000000003310

77. Nauclér P, Huttner A, van Werkhoven CH et al (2020) Impact of time to antibiotic therapy on clinical outcome in patients with bacterial infections in the emergency department: implications for antimicrobial stewardship. Clin Microbiol Infect. https://doi. org/10.1016/j.cmi.2020.02.032

78. Liu VX, Fielding-Singh V, Greene JD et al (2017) The timing of early antibiotics and hospital mortality in sepsis. Am J Respir Crit Care Med 196:856-863. https://doi.org/10.1164/rccm. 201609-18480C

79. Seymour CW, Gesten F, Prescott HC et al (2017) Time to treatment and mortality during mandated emergency care for sepsis. N Engl J Med 376:2235-2244. https://doi.org/10.1056/NEJMo a1703058

80. Kashiouris MG, Zemore Z, Kimball Z et al (2019) Supply chain delays in antimicrobial administration after the initial clinician order and mortality in patients with sepsis. Crit Care Med 47:1388-1395. https://doi.org/10.1097/CCM.0000000000 003921

81. Peltan ID, Brown SM, Bledsoe JR et al (2019) ED door-to-antibiotic time and long-term mortality in sepsis. Chest 155:938-946. https://doi.org/10.1016/j.chest.2019.02.008

82. IDSA Sepsis Task Force (2018) Infectious diseases society of America (IDSA) POSITION STATEMENT: why IDSA did not endorse the surviving sepsis campaign guidelines. Clin Infect Dis 66:1631-1635. https://doi.org/10.1093/cid/cix997

83. Gonçalves-Pereira J, Póvoa P (2011) Antibiotics in critically ill patients: a systematic review of the pharmacokinetics of $\beta$-lactams. Crit Care 15:R206. https://doi.org/10.1186/cc10441

84. Roberts JA, Pea F, Lipman J (2013) The clinical relevance of plasma protein binding changes. Clin Pharmacokinet 52:1-8. https://doi.org/10.1007/s40262-012-0018-5

85. De Winter S, Wauters J, Meersseman W et al (2018) Higher versus standard amikacin single dose in emergency department patients with severe sepsis and septic shock: a randomised controlled trial. Int J Antimicrob Agents 51:562-570. https://doi.org/ 10.1016/j.ijantimicag.2017.11.009

86. Vardakas KZ, Voulgaris GL, Maliaros A et al (2018) Prolonged versus short-term intravenous infusion of antipseudomonal $\beta$-lactams for patients with sepsis: a systematic review and metaanalysis of randomised trials. Lancet Infect Dis 18:108-120. https://doi.org/10.1016/S1473-3099(17)30615-1

87. Roberts JA, Taccone FS, Lipman J (2016) Understanding PK/ PD. Intensive Care Med 42:1797-1800. https://doi.org/10.1007/ s00134-015-4032-6

88. Abdul-Aziz MH, Lipman J, Akova M et al (2016) Is prolonged infusion of piperacillin/tazobactam and meropenem in critically ill patients associated with improved pharmacokinetic/pharmacodynamic and patient outcomes? An observation from the defining antibiotic levels in Intensive care unit patients (DALI) cohort. J Antimicrob Chemother 71:196-207. https://doi.org/10.1093/jac/ dkv288 
89. Abdul-Aziz MH, Alffenaar J-WC, Bassetti M et al (2020) Antimicrobial therapeutic drug monitoring in critically ill adult patients: a position paper. Intensive Care Med 46:1127-1153. https://doi. org/10.1007/s00134-020-06050-1

90. Annane D, Sébille V, Charpentier C et al (2002) Effect of treatment with low doses of hydrocortisone and fludrocortisone on mortality in patients with septic shock. JAMA 288:862-871. https://doi.org/10.1001/jama.288.7.862

91. Annane D, Renault A, Brun-Buisson C et al (2018) Hydrocortisone plus fludrocortisone for adults with septic shock. N Engl J Med 378:809-818. https://doi.org/10.1056/NEJMoa1705716

92. Sprung CL, Annane D, Keh D et al (2008) Hydrocortisone therapy for patients with septic shock. N Engl J Med 358:111-124. https://doi.org/10.1056/NEJMoa071366

93. Annane D, Bellissant E, Bollaert P-E et al (2009) Corticosteroids in the treatment of severe sepsis and septic shock in adults: a systematic review. JAMA 301:2362-2375. https://doi.org/10. 1001/jama.2009.815

94. Sligl WI, Milner DA, Sundar S et al (2009) Safety and efficacy of corticosteroids for the treatment of septic shock: a systematic review and meta-analysis. Clin Infect Dis 49:93-101. https://doi. org/10.1086/599343

95. Volbeda M, Wetterslev J, Gluud C et al (2015) Glucocorticosteroids for sepsis: systematic review with meta-analysis and trial sequential analysis. Intensive Care Med 41:1220-1234. https:// doi.org/10.1007/s00134-015-3899-6

96. Dellinger RP, Levy MM, Rhodes A et al (2013) Surviving sepsis campaign: international guidelines for management of severe sepsis and septic shock: 2012. Crit Care Med 41:580-637. https://doi.org/10.1097/CCM.0b013e31827e83af

97. Venkatesh B, Finfer S, Cohen J et al (2018) Adjunctive glucocorticoid therapy in patients with septic shock. N Engl J Med 378:797-808. https://doi.org/10.1056/NEJMoa1705835

98. Dellinger RP, Levy MM, Carlet JM et al (2008) Surviving Sepsis Campaign: international guidelines for management of severe sepsis and septic shock: 2008. Crit Care Med 36:296-327. https://doi.org/10.1097/01.CCM.0000298158.12101.41

99. Rygård SL, Butler E, Granholm A et al (2018) Low-dose corticosteroids for adult patients with septic shock: a systematic review with meta-analysis and trial sequential analysis. Intensive Care Med 44:1003-1016. https://doi.org/10.1007/ s00134-018-5197-6

100. Annane D, Bellissant E, Bollaert PE et al (2019) Corticosteroids for treating sepsis in children and adults. Cochrane Database Syst
Rev 12:CD002243. https://doi.org/10.1002/14651858.CD002 243.pub4

101. Marik PE, Khangoora V, Rivera R et al (2017) Hydrocortisone, vitamin $\mathrm{C}$, and thiamine for the treatment of severe sepsis and septic shock: a retrospective before-after study. Chest 151:12291238. https://doi.org/10.1016/j.chest.2016.11.036

102. Moskowitz A, Andersen LW, Huang DT et al (2018) Ascorbic acid, corticosteroids, and thiamine in sepsis: a review of the biologic rationale and the present state of clinical evaluation. Crit Care 22:283. https://doi.org/10.1186/s13054-018-2217-4

103. Chang P, Liao Y, Guan J et al (2020) Combined treatment with hydrocortisone, vitamin $\mathrm{C}$, and thiamine for sepsis and septic shock: a randomized controlled trial. Chest 158:174-182. https:// doi.org/10.1016/j.chest.2020.02.065

104. Fujii T, Luethi N, Young PJ et al (2020) Effect of vitamin C, hydrocortisone, and thiamine vs hydrocortisone alone on time alive and free of vasopressor support among patients with septic shock: the VITAMINS randomized clinical trial. JAMA 323:423-431. https://doi.org/10.1001/jama.2019.22176

105. Iglesias J, Vassallo AV, Patel VV et al (2020) Outcomes of metabolic resuscitation using ascorbic acid, thiamine, and glucocorticoids in the early treatment of sepsis: the ORANGES trial. Chest 158:164-173. https://doi.org/10.1016/j.chest.2020.02.049

106. Wani SJ, Mufti SA, Jan RA et al (2020) Combination of vitamin $\mathrm{C}$, thiamine and hydrocortisone added to standard treatment in the management of sepsis: results from an open label randomised controlled clinical trial and a review of the literature. Infect Dis (Lond) 52:271-278. https://doi.org/10.1080/23744235.2020. 1718200

107. Shi R, Tie H (2020) Benefit of hydrocortisone, thiamine, and vitamin $\mathrm{C}$ for patients with sepsis or septic shock? Too early to draw conclusions. Crit Care 24:431. https://doi.org/10.1186/ s13054-020-03153-5

108. Hager DN, Hooper MH, Bernard GR et al (2019) The Vitamin $\mathrm{C}$, thiamine and steroids in sepsis (VICTAS) protocol: a prospective, multi-center, double-blind, adaptive sample size, randomized, placebo-controlled, clinical trial. Trials 20:197. https:// doi.org/10.1186/s13063-019-3254-2

Publisher's Note Springer Nature remains neutral with regard to jurisdictional claims in published maps and institutional affiliations. 